\title{
Modified Instructional Teaching Method
}

\section{Luís Manoe}

Student, St. Thomas University of Mozambique, Mozambique

Corresponding Author: Luís Manoe

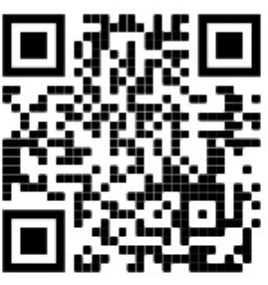

Article Info

Article history:

Received 05 January 2020

Received in revised form 12

January 2020

Accepted 21 February 2020

Keywords:

Language Teaching

Modified Instruction

Classroom Management
Abstract

Competency-based Language Teaching (CBLT) causes character education issue and its competence in facing a complex social circumstance which is quite conspicuous when implementing in national scale. Content-based Instruction (CBI) covers students and teacher proficiency that is considered not effective if the implementation does not take material and students' different competence into account. Cooperative Language Learning (CLL) weakness shows a feasible challenging with the classroom discussion dynamics and the allotted time. The weakness shows one leads to a broad scale, the other one causes teacher and students and the last costs the practical implementation.

\section{Introduction}

CBT is adopted from CBE (Competency-based Education) which considers output more than input (Richards \& Rodgers, 2001). CBT clusters students based on their competency and directly addresses students lack in performing language skill (Stallard et al., 2013). Teachers in designing the syllabus are obliged to meet the students need in order to accustom students to their target language environment.

Specifically, competency element involves everything contributes to learner successful performance in target language environment which includes particular knowledge and skill (Richards \& Rodgers, 2001). The prominent results of CBT course develop learner's in understanding context and performing appropriate language competencies in prospective working environment i.e. understanding instruction, giving appropriate respond, reading charts, labels and forms. The target language mastery is taught based on the students' proficiency stage where the standard of success relies on the students' triumph meeting required ability after the course.

Assessment in CBT is meritorious with three educational assessment involved. Placement test that is essential to categorise students' current stage ability (Glickman, 2008). Formative assessment that helps teacher to determine whether learners understand and to improve their instruction. Summative assessment which values students' success during the course. There is also possibility of employing diagnostic assessment that assists teacher in developing their instruction through analysing problems faced during the course. Those assessments' fruitfulness is feasible in CBT by means of its concrete measure.

Teachers are more to be instructor rather than giving lecture which result to a better teaching outcome. Lecture in classroom interaction most likely reduces students' necessary practice during the allotted time. When it comes to language learning, it obviously requires learner to have exposure to the targeted language both receptively and productively. Furthermore, the study of Hackathorn, Solomon, \& Blankmeyer, (2011) revealed that lecturing result to less 
knowledge acquisition and lack of real application. They added that not only contribute to accurate proficiency of target language application, it also promotes preferable comprehension through group discussion. The shift of teacher position in CBT is therefore effective when it comes to outcome-base.

First, it only prepares the student for a specific condition. Focus on specific environmental case will put aside creativity and innovation (Bataineh \& Tasnimi, 2014). It is important to note that the essence of education is to equip students with knowledge and skill to face the complex world dynamics. Brady (2006) has criticized Competency-base Teaching which negatively influences huge scale of education. The worst scenario when generally relying on CBT in national scale is high probability to obstruct human civilization advancement. This claim sounds tremendously assumptive but given the fact that what has driven human to current state civilization is because the existence of curiosity which is the basic stage of creativity and innovation.

Bataineh \& Tasnimi (2014) suggest that this approach espouses students to be individualistic. Radically thinking, any approach, model, technique and method in teaching have implication that forms students' personal character. CBT give exposure on how individual success is critically matter for anyone. It neglects the promotion of cooperative work that helps solve problem better. For some countries, education is essential to strengthen their identity. Indonesia, for instance, has emphasized character education in its curriculum as counter balance of their moral degradation issue. CBT for such purpose is therefore less recommended.

\section{Cooperative Language Learning}

The leading principle is promoting cooperation within students (Richards \& Rodgers, 2001). The classroom climate is designed to encourage students working together by problem given to solve. Students are obliged to contribute by involving and contributing to group discussion. While teacher is assigned as facilitator that offers students opportunity to work in by paying attention and sharing opinion.

Another principle is developing communicative competence (Richards \& Rodgers, 2001). CLL in its implementation positions students as the centre of the teaching learning process. It is done by paring or grouping students with a more dynamic interactive discussion. This mechanism conspicuously shapes students' communicative skill.

It is believed to increase motivation in learning. Teacher during the learning process assesses students by their performance that tends to be appreciative. The stimulating learning climate through an attractive learning model encourages students develop their communicative skill and critical thinking. Through discussion of solving the problem given, the sense of learning is urged.

CLL is further leading up to group working that promotes cognitive development. The discussion of the students in the group is coming from different proficiency. A major finding (Wilkinson, 2016) suggests that discussion result to better knowledge acquisition. Distinct proficiency in understanding context, concept or problem compels a glimpse of material discussed. Through process of exchanging information in the discussion, students understanding are therefore faster to be constructed.

It is not obvious that students will perform expected group dynamic application. Individuals are different by nature and it is more challenging to guide students to work hand in hand. Conflict between different perception and ideas are inevitable during a discussion. Considering that one teaching allotted time could not facilitate students with time they need to get their work done, learners would not completely understand a concept or solve a problem. This is possible to take place if teacher groups students without considering their competence. Furthermore, teacher pushes ahead students in their group discussion, while this pressure my 
cost students' motivation in learning. Considering this constraint, it is not concrete to assume that students would definitely have done the process in cooperative learning.

\section{Content-Based Instruction}

The core idea of CBI focuses on the material substance (Richards \& Rodgers, 2001). Its concern puts aside language grammatical approach as the material. The practice exposes the use of real communication and exchange of information. The acquisition of content is done through language rather than stud of language.

Another basic principle of this approach focuses on promoting learning autonomy within students by attracting students through interesting material (Richards \& Rodgers, 2001). The focus of the material is determined by its affection on students learning. The material used is relevant to student's life, interest or goal.

The similarities of these principles can be seen from its mechanism in addressing learners' need in learning. The development of students' competence through a specific target knowledge and skill in language teaching is examined by their performance during learning process rather than final test requirement.

They likewise shape students' personality in learning. Motivation in learning is a key factor that determine students' willingness. Since it is found that comprehension and performance are more espoused when students have a strong stimulus (Ahmadi, 2017), the similarity therefore promotes learning autonomy.

Differences are minor to be found. They only differ seen from the position and role of the teacher. Consecutively, one stays as instructor to guide the students during the learning activity. Another one puts teacher as facilitator that provides further information and correcting students misunderstanding. The last position teacher as guide, information centre and instructor.

CBI contributes to social collaborative attitudes. Problem solving process obviously builds bounding among learners. Knowledge sharing occurrence naturally shapes their role in group. Different characteristics of individuals are recognised by each and their roles are determined by means of each own proficiency and expertise. A good bounding within students is determent

It likewise provides extensive and contextualised-language knowledge. The course provision equips students with real use of linguistic competence in different social context. Although the content is determined based on attractive material and learners' goals of the target language, but the learning activity habituate students with critical thinking that contributes to their aptitude dealing with complex social context.

Material prepared and instructed to discuss may not meet students' proficiency. in language proficiency case, students might get excited by the material, but a course that requires students to speak English would be a burden in conveying their ideas. In EFL learner context, this problem always takes place and becomes a huge issue for the teacher to address. In the comprehension aspect, teacher may provide material that is beyond students understanding. Thus, background knowledge should be there to advocate students in order for the learner to be able to engage in the dynamic of the discussion. It will cost the allotted time for discussion. This proficiency issue is quite peremptory for the success of CBI.

\section{Similarities and Differences}

Similarly, the three approaches cost possibility of students' personal character in learning whether it is their motivation or personal competence. These weaknesses are avoidable by making sure the provision well prepared. While the differences in weakness can be seen in its scale of casualty. CBLT causes character education issue and its competence in facing a complex social circumstance which is quite conspicuous when implementing in national scale. CBI covers students and teacher proficiency that is considered not effective if the 
implementation does not take material and students' different competence into account. CLL weakness shows a feasible challenging with the classroom discussion dynamics and the allotted time. The weakness shows one leads to a broad scale, the other one causes teacher and students and the last costs the practical implementation.

The similarities of the three approach can be seen from its focus in addressing students' development in learning. As suggested that cooperativeness of students would escalate communicative competence (Ahmed \& Pawar, 2018), the strengths mostly substantiate the acquisition of linguistic knowledge and skill. The implementation facilitates learners with knowledge sharing process through discussion, cooperation, and problem solving.

The differences rely on its relativity in of the material taught. CBLT takes students need in learning language as the outcome of the course, CLL focuses more on the target language exposure through social communicative competence in learning, while CBI ensures the learners to have enticement to excite them in learning.

\section{Modification}

in public school context, students are obliged to have inputs that is standardised by government. The CBLT modification takes national competency standard as the outcome source. CBI would contribute to the provision of the course's content material that is considered attractive and stimulating for students learning behaviour. CLL principles applied as a mechanism to complement students with social communicative competence and critical thinking.

As an instance, taking place in one full teaching learning process about 90 minutes is described in the following paragraph.

The material taught is assimilating students with kinds of text and producing one kind of text for each group. The first five minutes would be a praying and greeting session. Five minutes ahead, teacher is reflecting previous lesson to brainstorm their understanding. The next five minutes, teacher explains the classroom activity and groups the students based on students' competence. Teacher's glasses on learner that is considered capable of leading the group based on their comprehension capability would be vital in ensuring expected classroom dynamic occurred. Students are given thirty minutes to discuss the concept of different types of text. The next twenty minutes students are producing their own text with different types for each. During the allotted of the discussion process, students are able to ask question if the group stuck to understand concept. Because there are few numbers of groups, teacher is unable to observe students' participation in the discussion. Therefore, each student in the group will be asked to take note ideas produced by peers. By the collection of the note, teacher would be able to assess students' contribution and willingness in learning.

The next fifteen minutes, students are then grouped based on kinds of text they are writing. During this allotted time, students are required to read their peer writing and to comment either it lacks or not. Remaining fifteen minutes, teacher point a representative of each text group to explain about their own text concept and tricks the reveal in writing the text.

\section{Potential Problems}

To identify the possible problems during the practice of the modification, associating the practice with the teaching purpose could be a good standard. The problem probably takes place during within the text production. Even if discussion runs well, students' competence in producing text might be different. Reflecting to previous teaching experience, some students are incapable of producing writing in limited time. The process of writing text based on specific type examine creativity. This is less creative when racing with time because idea does not come spontaneously. Understanding concept and producing text should be done in different period of time. 


\section{Conclusion}

The similarities of the three approach can be seen from its focus in addressing students' development in learning. The differences rely on its relativity in of the material taught. CBLT takes students need in learning language as the outcome of the course, CLL focuses more on the target language exposure through social communicative competence in learning, while CBI ensures the learners to have enticement to excite them in learning. In implementing this modified method, Understanding concept and producing text should be done in different period of time.

\section{References}

Ahmed, S. T. S., \& Pawar, S. V. (2018). Communicative competence in English as a foreign language: Its meaning and the pedagogical considerations for its development. The Creative Launcher, 2(4), 301-312.

Ahmadi, M. R. (2017). The Impact of Motivation on Reading Comprehension, 1-7.

Bataineh, K. B., \& Tasnimi, M. (2014). Competency-Based Language Teaching, Express, an International Journal of Multi Disciplinary Research, 1(7).

Brady, L. (2006). Outcome - based education: a critique, (March 2015), 37-41. https://doi.org/10.1080/0958517960070102

Glickman, N. (2008). Cognitive-behavioral therapy for deaf and hearing persons with language and learning challenges. Routledge.

Hackathorn, J., Solomon, E. D., \& Blankmeyer, K. L. (2011). Learning by Doing: An Empirical Study of Active Teaching Techniques, Journal of Effective Teaching 11(2), 40-54.

Richards, J. C., \& Rodgers, T. S. (2001). Approaches and Methods in Language Teaching. Cambridge University Press.

Stallard, P., Phillips, R., Montgomery, A. A., Spears, M., Anderson, R., Taylor, J., ... \& Georgiou, L. (2013). A cluster randomised controlled trial to determine the clinical effectiveness and cost-effectiveness of classroom-based cognitive-behavioural therapy (CBT) in reducing symptoms of depression in high-risk adolescents. Health technology assessment (Winchester, England), 17(47), vii.

Wilkinson, I. A. G. (2016). Discussion methods, (January 2009). In book: Psychology of classroom learning: An encyclopedia. Publisher: Gale/Cengage 